\title{
Restructuring Industries: The Carrot and the Stick
}

\author{
ROGER SHERMAN* \\ Department of Economics, University of Houston
}

\begin{abstract}
Restructuring brings market incentives into formerly monopolized network industries and raises a host of questions about whether the carrot of profit seeking can be disciplined by the stick of competition. In the telephone industry access pricing is an issue, and major problems are illustrated. In the electricity industry other problems are described and possible solutions are briefly sketched.
\end{abstract}

\section{Introduction}

Market regulation has been transformed in the last quarter century, ${ }^{1}$ from sprawling territorial monopolies to deregulated and restructured industries. Old monopolies were vertically integrated across local and long-distance telephone services or across generation and transmission of electricity. Restructuring has separated those functions and opened some of them to competition. Unlike deregulation, which turns market regulation over to competitive markets, restructuring aims to harness market incentives to achieve efficiency in a partly regulated environment.

Firms in markets are driven by incentives of two broad kinds, (1) the carrot of profit (which may bring low prices to win consumers in competitive environments or bring high prices and price discrimination in monopolistic ones) and (2) the stick of competitor's costs. The carrot is forward looking; it tempts the firm, usually in its pricing, to act in ways that may reflect costs more accurately and promote welfare, or instead to exploit market power. The stick looks sideways, or over the shoulder, out of concern that others may achieve lower costs and win customers away with lower prices. When the stick is strong it can dominate the carrot.

The carrot and the stick have been introduced to traditionally regulated firms through new mechanisms such as price-cap regulation. More ambitiously, deregulation was imposed to bring back the competitive stick where possible, but deregulation will not be treated here. ${ }^{2}$ Attention goes instead to the still more ambitious step of restructuring regulated industries,

* Mailing address: Department of Economics, University of Houston, Houston, TX 77204-5019. E-mail: rsherman@uh.edu I am grateful to Emin Dinlersoz, Stephen Littlechild, Gerry Moohr, Dennis Weisman, and an anonymous referee for comments on an earlier draft; they cannot be blamed for errors that remain.

${ }^{1}$ For a review of changes in law, see Kearney and Merrill (1998).

${ }^{2}$ For a brief treatment of deregulation see Sherman (2001a). 
retaining regulation in some parts but trying to apply the healthy carrot or the brutal stick to other parts. Specifically, our topic is the restructuring of the telephone and electricity industries.

Early regulation of industries tried to avoid monopoly behavior but seldom attended to matters of the carrot or the stick. A rate-of-return regulated monopoly faced only a slice of the carrot, for instance, because profit controls pared its profit incentive. It faced a twig rather than a stick in the weak form of unsystematic invidious comparisons to others' costs. Its prices were based primarily on its own costs, which virtually eliminated the stick. When costs are high, prices are high, and the inefficient firm goes unpunished.

To recover the stick, competitors have been granted access to once-monopolized essential facilities as part of the restructuring of formerly regulated network industries. Tracks of one railroad have been made available to other railroads for many years. Pipelines for natural gas can be an essential facility for the gas distributor who needs access to pipelines for transportation of natural gas. ${ }^{3}$ When long-distance telephone service providers were granted access to local monopoly exchange networks in 1984 they were forced to compete. ${ }^{4}$ Access to transmission wires enables an independent generator to participate in a wholesale market for electricity. ${ }^{5}$ Even mail delivery for mail transporters, or for those who sort and code mail to make it easier for the Postal Service to handle, raises access pricing issues. ${ }^{6}$

We begin by briefly describing in Section 2 some major changes in how public utilities are regulated, because these changes can influence restructuring. Section 3 treats the restructuring of telecommunications, where access to networks plays a crucial role. The pricing of access to telephone networks is regulated in telecommunications, presumably to restrain the carrot and promote the stick of competition, but regulation is so strong it may be in conflict with such aims. Section 4 describes restructuring in electricity. Access is also important there, as access to transmission networks supports competition among generators in wholesale electricity markets. New institutions are still being developed to coordinate supply and allow broader responses in demand. Section 5 contains a conclusion.

\section{Changes in industry regulation}

Even apart from deregulation and restructuring, industry regulation has changed in the last thirty years. Growing as it did out of compromises in court cases, rate-of-return regulation was not well designed, and it gave virtually no attention to incentives in the regulated firm. Mechanisms were developed to overcome this weakness of incentives in regulated firms. An external performance standard was created as a stick through "yardstick competition", for example, which requires a firm to match (or to exceed) a standard that is based on other similar firms' costs. But the greater problem is to resuscitate the carrot, which can be accomplished by price-cap regulation. Section 2.1 traces ways to bring the stick to regulated industries and Section 2.2 shows how price-cap regulation can lead the carrot to induce efficient pricing.

${ }^{3}$ For a description of this access in the natural gas industry see Michaels (1993).

${ }^{4}$ For a description of changes in telecommunications, see Temin (1987).

${ }^{5}$ For a description of this transition to competition in electricity see Joskow (forthcoming).

${ }^{6}$ For a description of postal worksharing discounts see Sherman (2001b). 


\subsection{Introducing the stick}

Rate-of-return regulation offered little incentive for cost control, and even less for efficient pricing. Its lack of efficiency incentive was effectively analyzed more than seventy years ago, ${ }^{7}$ and a bias toward capital as an input was diagnosed forty years ago by Averch and Johnson (1962) and by Wellisz (1963). ${ }^{8}$ But better ways of motivating efficient operation were not at hand.

Ways to pressure regulated firms into controlling their costs were gradually developed. A cost standard from the performance of other firms was proposed by Shleifer (1985), for instance, as yardstick competition. The stick of other firms' performances would be used to discipline each regulated firm. This desire for the benefits of comparison influenced Britain to create two telephone companies in 1982, and to create more electricity generators when deregulation began in that industry in 1990. Interpreted broadly, the yardstick idea also had effects in the U.S. electricity industry, since part of the drive to restructure that industry came in states with less efficiently produced, higher cost, electricity. Those states were suffering in competition with low-cost-electricity states to attract and hold business and industry.

Two other early proposals to raise economic welfare (1) used information about demand to characterize welfare, and (2) auctioned monopoly rights to force constructive bidding. Loeb and Magat (1979) proposed to pay a monopoly according to an estimate - based on demand information - of the consumer surplus it generated, and then auction the right to be that monopoly. This scheme could stir the carrot by rewarding the firm according to gains in consumer surplus, and through the auction it could awaken the stick as well. The idea of auctioning a monopoly position goes back to Chadwick (1859), who had applicants bid for the monopoly position based on the price they would set for customers (low price wins). He thus converted the carrot of monopoly into the stick of having to beat all other contenders "for the field". Such bidding for monopoly was modernized by Demsetz (1968) and was applied to cable television franchises, as described by Williamson (1976). ${ }^{9}$ Welfare was now in play as part of the goal of monopoly regulation, but how best to pursue it was still not clear.

The idea of using "regulatory lag", the delay between rate cases, for incentive benefits came from Baumol (1968). He argued that the regulated firm would have incentive to control its costs while it was stuck with unchanging prices between rate cases, the fixed prices essentially serving as a stick. So he proposed a specific time period between rate cases, such as three years or five years, when prices would remain fixed. Britain designed a form of telephone company regulation that made regulatory lag permanent by adjusting price according to a price index, and called it "price-cap" regulation. In the absence of competition, it proved to be an impressive elixir. Using a price index as a benchmark avoids reference to the firm's own cost as a basis for pricing, which preserves the stick. Since the firm's own costs do not influence its prices, the firm is motivated to control its cost.

In practice, price-cap regulation comes with complications. The measure of price level change may be imperfect. Regulators may err in setting a rate of technological progress, which is usually demanded as a reduction in allowed costs. Estimating the potential for

\footnotetext{
${ }^{7}$ See Montgomery (1931).

${ }^{8}$ Jones (1983) reviews, and adds further empirical support for, this bias toward the use of capital.

${ }^{9}$ See also Laffont and Tirole (1987) and McAfee and McMillan (1987).
} 
technical progress can be especially difficult in newly privatized industries, yet it must be done in advance as part of the basis for the price cap. When errors are made in anticipating such progress, and adherence to a faulty price-cap would allow too much or too little profit to the firm, its actual cost may be used to influence price. The compromise that results is less perfect than pure price caps, but can still improve efficiency incentives in the firm. ${ }^{10}$ Over the last twenty years in the United States, price caps have become the regulatory mechanism of choice in the local telephone industry. ${ }^{11}$

\subsection{How price-cap regulation exploits the carrot}

Remarkably, price-caps can exploit the carrot to elicit socially desirable pricing, specifically Ramsey (1927) pricing, instead of monopolistic pricing. Vogelsang and Finsinger (1979) showed that if constrained in a special way, a multiproduct firm that was free to choose its prices under price caps would make socially desirable price choices. ${ }^{12}$ This finding is important because, although it was not widely acknowledged, a major problem of rate-ofreturn regulation was to control the firm's natural tendency to prefer monopolistic pricing. ${ }^{13}$

The price-cap constraint on price adjustment can be described briefly. Suppose for simplicity that there is no change in price level or technology from period to period. The firm is to take its new price for each service, multiply it times last period's quantity for that service, and add up the resulting revenues to obtain the total revenue that procedure will project. The constraint is that this total projected revenue cannot exceed last period's total revenue.

Consider an example involving two goods, where $P_{1}{ }^{\prime}$ and $P_{2}{ }^{\prime}$ are prices and $Q_{1}{ }^{\prime}$ and $Q_{2}{ }^{\prime}$ are quantities for the two goods last period. The firm is free to choose $P_{1}$ and $P_{2}$ for the current period, but in doing so must meet the constraint,

$$
P_{1} Q_{1}^{\prime}+P_{2} Q_{2}^{\prime} \leq P_{1}^{\prime} Q_{1^{\prime}}+P_{2}^{\prime} Q_{2}^{\prime}
$$

Thus, the projected revenue to be obtained by new prices, using old quantities, must not exceed the old revenue. This inequality may be rearranged in the form,

$$
\left(P_{1} Q_{1}^{\prime}+P_{2} Q_{2}^{\prime}\right) /\left(P_{1}^{\prime} Q_{1}^{\prime}+P_{2}^{\prime} Q_{2}^{\prime}\right) \leq 1
$$

The term on the left hand side of the inequality is the Laspeyres price index. This leads directly to allowing prices to change in keeping with price-level change, by replacing 1 with whatever price index is appropriate for period-to-period price-level change. And a required rate of technological improvement can be subtracted to lower allowed cost as well.

\footnotetext{
${ }^{10}$ See Wolak (1998) for discussion of this trade off between referring to the firm's actual cost and avoiding any such reference. Combinations of cost-based and price-cap regulation that involve sharing are examined by Weisman $(1993,1994)$.

${ }^{11}$ See Ai and Sappington (2002).

${ }^{12}$ The process is not perfect; see Sappington (1980) and Cox and Isaac (1987).

${ }^{13}$ For examples of pricing biases under rate-of-return regulation see Sherman and Visscher (1982) and Sherman (1989a, Ch. 9). Sherman (1989b) shows how peak and off-peak pricing periods are not motivated under rate-of-return regulation, but if such periods are used the firm's preferred peak-load pricing period will be shorter than is optimal. Eckel (1987) provides evidence of pricing biases.
} 
Intuitively, the constraint (1) on the monopoly firm breaks the connection with current demand that allows the monopoly to calculate marginal revenue. There can be no marginal revenue calculation because the firm evaluates the effect of prices using quantities that are not affected by those chosen prices. Vogelsang and Finsinger (1979) showed that repeated application of this pricing rule induces Ramsey prices. For the process to work ideally, $Q_{{ }^{\prime}}{ }^{\prime}$ and $Q_{2}{ }^{\prime}$ should be next period's quantities, but of course those quantities cannot be obtained without using demand information that might bring the dreaded marginal revenue into play. In a stable environment, however, period-to-period quantities of a service can be expected to converge.

To see the operation of this procedure consider a profit-maximizing firm selling two goods or services with zero cross-elasticities of demand. While the firm must satisfy the constraint in (1), its profit is $\pi=P_{1} Q_{1}+P_{2} Q_{2}-C\left(Q_{1}, Q_{2}\right)$. For simplicity, marginal cost of each good or service will be assumed constant at $C_{i}(i=1,2)$ and again there is no pricelevel change. The firm then faces the Lagrangian problem,

$\left(P_{1}, P_{2}, \lambda\right)=P_{1} Q_{1}+P_{2} Q_{2}-\mathrm{C}_{1} Q_{1}-\mathrm{C}_{2} Q_{2}-\lambda\left(P_{1} Q_{1}^{\prime}+P_{2} Q_{2}^{\prime}-P_{1}^{\prime} Q_{1^{\prime}}-P_{2}^{\prime} Q_{2}^{\prime}\right)$.

Maximizing with respect to $P_{i}$ yields

$$
Q_{i}+P_{i} M Q_{i} / \mathrm{MP} P_{i}-C_{i} M Q_{i} / \mathrm{M} P_{i}-\lambda Q_{i}{ }^{\prime}=0
$$

Rearranging (3) yields

$$
\left(P_{i}-C_{i}\right) / P_{i}=\left(1-\lambda Q_{i}{ }^{\prime} / Q_{i}\right) / E_{i}
$$

where $E_{i}=\left(P_{i} / Q_{i}\right) /\left(M Q_{i} / \mathrm{MP} P_{i}\right)$ is the own-price elasticity of demand for the $i$ th good. The Lagrange multiplier, $\lambda$, is modified by $Q_{i}{ }^{\prime} / Q_{i}$, which should be close to 1 (less than 1 if outputs increase in later time periods). Equation (4) approximates a Ramsey (1927) pricing rule. It can be expected to converge to the pure rule because $1-\lambda Q_{i}{ }^{\prime} / Q_{i}$ will approach $1-\lambda$ , the Ramsey multiplier, as period-to-period changes grow small and $Q_{i}$ converges to $Q_{i}{ }^{\prime}$.

Thus, new regulatory instruments were created and applied by the $1980 \mathrm{~s}$, some to enliven the stick of competition (yardsticks, monopoly auctions, price caps), and some to create a carrot leading toward more efficient pricing (price caps). These ideas improved regulation and can have a role in restructured industries.

\section{$3 \quad$ Restructuring telecommunications}

Restructuring a formerly regulated industry depends on markets that are designed rather than naturally evolved. Access for newcomers to some network usually plays a crucial role, because it brings competition to networks that were previously controlled by a monopoly. In such a complex setting the carrot may have unwanted effects. The first problem is to see what combination of carrot and stick might be achieved, and to ask how effectively they can serve economic welfare.

Two main types of access arise in telecommunications networks. First, each of two networks may originate calls to parties served by the other network, so they need access to 
each other's networks to complete those calls. This is like two railroads using each other's tracks so each railroad can deliver for its own customers, and the services are complementary. ${ }^{14}$ Second, the owner of an established network has advantages over potential entrants, in part from its network externalities, and to improve opportunities for entrants the network owner may be required to grant access to its essential facilities so entrants can combine them with their own facilities to provide service to customers. This is like having one railroad use the tracks and other equipment of a second railroad to serve customers in direct competition with that railroad because the ultimate services are substitutes for each other. $^{15}$

Telecommunications networks have important complementarities when a call originating in one network is completed on another. But by acting independently the networks will ignore their complementarity, and make lower profit while raising the ultimate price to consumers. So if scope is given to the carrot in such a setting, decentralized actions can be inefficient, since each network sees only part of the complementary relationship. Once a network owner grants access to a competitor their relationship is even more complicated because their services are substitutes. Then the terms of access can be crucial to the efficiency of the ultimate service offerings.

Pricing incentives between interconnected networks are first sketched in Section 3.1, and then principles for pricing access are reviewed in Section 3.2. Federal regulation of access under the Telecommunications Act of 1996, which was intended to make the industry more competitive, will then be described in Section 3.3.

\subsection{Pricing incentives between telephone networks}

Once competitors function through interconnected networks, they may face carrots as well as sticks. Network operators will often want the networks designed to the same standard, since compatibility allows interconnection that expands the benefits of network externalities. With interconnection, each network can reach more customers, and the networks are complements in the production of telephone service. For simplicity, the externality effect itself will not be treated here, in order to focus attention on other aspects of pricing for telephone services when networks are interconnected. ${ }^{16}$ With the networks separately owned, however, they must first reach agreement on terms for connecting each other's calls, and setting such terms is the main new issue raised by the interconnection of networks. ${ }^{17}$

\subsubsection{Interconnection of complementary telephone networks}

Each network collects a fee from the customer who originates a call, so the network may then have to compensate any other network that helps to complete the call. If the recipient of the call shared in paying its cost, a different pricing arrangement could result. Because the

\footnotetext{
${ }^{14}$ Railroads using each others' tracks is a long standing example of access. By exchanging access rights, each railroad can broaden its reach through network externalities, so access is motivated on a decentralized basis.

${ }^{15}$ This is also like having a dominant newspaper company in a city print the newspapers of other newspaper companies so they can compete with it. A proposal to preserve newspaper competition by this means was made by Sherman (1976).

${ }^{16}$ Including network externalities would tend to make conclusions reached even stronger.

${ }^{17}$ For thorough treatment of this problem see Laffont and Tirole (1998a, 1998b).
} 
practice of having the initiator pay for calls is so widespread, that practice is assumed here. ${ }^{18}$ When only two networks are interconnecting - as when a long-distance company wants to complete a call through a local network - the bargaining may seem quite simple. But there is a complementary vertical relationship between long-distance and local networks that raises a problem much like double marginalization in manufacturer-retailer relationships, ${ }^{19}$ except that here double marginalization can apply in two directions. The Telecommunications Act of 1996 envisioned local and long-distance service providers competing in each others' domains, and thus facing access pricing decisions in both directions.

The double marginalization possibility is not unusual. When a manufacturer sells to a retailer who resells to consumers, for example, and each has some market power, the manufacturer will mark up its cost to set its price to the retailer, who accepts that price as a cost and marks it up again to set a price for consumers. The result is a higher price for consumers than a single integrated firm would set because the single firm would mark up its cost to consumers only once. A variety of vertical restraints, from franchising contracts to resale price maintenance, have been used by independent firms in an effort to avoid the effects of double marginalization, and antitrust law has gradually come to respect such restraints. ${ }^{20}$ Double marginalization can be a problem for independent telephone networks as they follow the carrot of profit seeking in interconnected networks. Since networks connect calls for each other, they can face double marginalization in two directions, and that possibility can be called double double marginalization.

Double double marginalization might be overcome when two telephone networks are symmetrical in the volume of calls they exchange with each other, because they then might see the advantage of charging access to each other at marginal cost. Setting the access price at marginal cost would allow each network to maximize profit efficiently when it marks up marginal costs in pricing to consumers. If one network is larger than the other in generating call volumes, however, the resulting lack of symmetry can change their incentives and interfere with their reaching agreement on an access price equal to marginal cost.

Suppose one network has many more customers than the other. Since it originates more calls, it depends heavily on access to the other network, so it is more like the manufacturer in the manufacturer-retailer example. It wants to avoid double double marginalization and can see the advantage of a low access fee. But the smaller network makes its money on access fees for completing the larger network's calls, and it would therefore resist low access fees. Such a difference in motivation can make agreement difficult on a common access fee that would overcome double double marginalization. To control this asymmetry in incentive, Carter and Wright (2003) even propose to let the larger network choose an access fee that will hold reciprocally, because the larger network ordinarily is motivated to set a lower (but not below cost), and thus more efficient, access fee.

\footnotetext{
${ }^{18}$ Sharing the cost of calls between initiator and recipient can improve pricing incentives. For analysis of effects of having recipients contribute to the cost of calls, see DeGraba (2001).

${ }^{19}$ Double marginalization occurs when both manufacturer and retailer independently mark up their products, and the final product price is higher than a joint manufacturer-retailer firm would choose.

${ }^{20}$ For examples, territorial or location restrictions that control competition among sellers of the same brand were allowed in Continental TV v. GTE Sylvania, 433 U.S. 36 (1977) and a form of resale price maintenance was supported in State Oil v. Kahn, 871 U.S. 96 (1997). The virtue of such restraints to antitrust authorities is that they enable firms to achieve efficiencies of integration without actually integrating.
} 


\subsubsection{Interconnection of substitute telephone networks}

Suppose now that two networks, Network 1 and Network 2, compete for the same customers. And suppose, for concreteness, that the fraction of Network 1's customers making calls to customers of Network 2 is equal to Network 2's share of the overall telephone market. More calls from Network 1 will tend to go to Network 2 as Network 2's share of the market is larger, and Network 1 will have to pay more access charges to Network 2 in order to complete them. If access fees are above marginal costs, Network 1 would prefer to complete those calls on its own network, which it can do by winning a larger market share. Of course the same argument applies to Network 2.

Competition for market share can develop even if product differentiation gives each network an element of market power in attracting some customers to its own network. As long as keeping calls within your own network as it grows larger can lower the net cost including access fees paid to the other network, that incentive to grow larger will still tend to induce more competitive pricing for telephone service to consumers. At the same time, the competition might inspire higher access fees as the competing networks attempt to raise each others' costs, so it will not ensure optimal pricing of access for networks or of telephone service for consumers.

Even though the networks are now substitutes, there is still complementarity between them, since they both support some calls and then might see the advantage of pricing access at marginal cost. Setting access fees closer to marginal cost will also moderate the urge to grow larger, since it lowers the cost of completing calls on rival networks. As noted in Section 3.1.1, the networks can exploit the complementarity of their services and share the benefits more easily as the volume of calls exchanged are more equal. The volume of calls between interconnected local exchange networks (LECs) will often be approximately equal, even when the LECs differ in size. Even though they might be able to tame double double marginalization by exchanging access at marginal cost, strategic motives based in part on size differences might get in the way. ${ }^{21}$

How can a firm enter this competition of networks for customers? ${ }^{22}$ Entry could be difficult against an incumbent owner of a network who already enjoys the benefit of network externalities. Interconnection can make local network competition possible, because it allows the entrant to reach customers of the incumbent network, and vice versa, thus broadening network externalities, but the entrant cannot easily build facilities to establish connections to its customers one by one. Foreseeing this difficulty while seeking competition, the Telecommunications Act of 1996 called for incumbent networks to offer elements of their facilities for lease to entrants. Examples of network elements are billing, signaling, or call switching services. Entrants could then build some of their own facilities and lease other

\footnotetext{
${ }^{21}$ Continuing with the assumption that the fraction of Network 1's customers making calls to customers of Network 2 is equal to Network 2's share of the overall telephone market, and vice versa, will tend to make the actual number of calls from one network to the other equal. To see that, suppose Network 1 is larger, with $\mathrm{N}$ customers, and Network 2 is smaller with $\mathrm{n}$. Then $\mathrm{N}(\mathrm{n} /(\mathrm{N}+\mathrm{n}))$ calls will go from Network 1 to Network 2, while $n(N /(N+n))$ calls will go from Network 2 to Network 1, and these two numbers are equal. Exchanging an equal number of calls would help the networks realize the advantage of pricing access at marginal cost to avoid double double marginalization. But the fraction of calls may not match the market shares, especially if smaller networks target commercial customers. A smaller network comprised of commercial called parties (for example, pizza sellers) might receive many more calls than it originates, and such a network might want to exploit a larger rival through high access prices.

${ }^{22}$ For analysis of entry and its effects in this setting, see Sappington and Weisman (1996).
} 
elements from the incumbent. Having incumbents and entrants as direct competitors makes efficient access pricing very important, so that whoever has the most efficient pricing structure can expect the most success.

\subsection{Pricing access to telephone networks}

The unrestrained carrot alone may not reliably bring optimal pricing to interconnected telephone networks. Two prominent approaches exist to guide access for interconnection. One policy settles for introducing the stick of competition into one vertical stage, or function, but prevents competition beyond that stage. Under terms of the 1982 court decision that opened the long-distance telephone service market, for example, local exchange carriers (LECs) were prevented from participating in other activities - such as long distance service on grounds that regulators would then have difficulty regulating. The LEC might be able to create advantages for its own long distance service, if it was allowed to provide it, which could cause inefficiencies that regulators might not detect. While regulation is simpler under such clear rules that simply bar LECs from long-distance markets, and it can bring the stick to long-distance providers, the economic costs could also be considerable. Possible economies of scope are not realized, for instance, because the firm is not allowed to offer combinations of local and long-distance services.

The second way to manage access spills across separate functions, and allows competition between the access provider and the firms that are granted access. The Telecommunications Act of 1996 took this step by allowing local network operators to compete against each other and to compete also in long-distance markets once they met requirements for opening their local markets to competition. This allows the most efficient organization to come into existence. But an error in setting the access price too high or too low can lead to inefficiency by inviting more service provision from a less efficient operator.

As noted earlier, requiring access to essential or bottleneck facilities is not new. ${ }^{23}$ But requiring access on a broad scale to create competition, while also controlling the price of such access, are new regulatory actions. ${ }^{24}$ The actions are justified on grounds that they foster competition where it did not exist before. Forcing access generally amounts to a significant redefinition of property rights, in that a monopoly owner of an essential facility even a regulated owner - no longer controls use of the facility exclusively. The power to regulate price is extended to a power to regulate a right of access along with its price.

Two main ideas guide access pricing. First is the efficient component pricing rule (ECPR), which is based on cost and is discussed in Section 3.2.1, and second is the familiar idea of Ramsey pricing, which is based on cost plus demand elasticity and is discussed in Section 3.2.2.

\subsubsection{Efficient component pricing for access}

The efficient component pricing rule (ECPR) is all about incentives. ${ }^{25}$ It prices access to bring efficient competition, which gives it the effect of a stick, and it also provides a carrot. The ECPR calls for an access price that equals the provider's direct cost of arranging access,

\footnotetext{
${ }^{23}$ See United States v. Terminal Railroad Association of St. Louis, 224 U.S. 383 (1912) and 236 U.S. 194 (1915).

${ }^{24}$ For a broad review of the essential facilities doctrine, see Lipsky and Sidak (1999).

${ }^{25}$ This idea was first proposed by Willig (1979). Important developments and applications have been made by William J. Baumol. See, for example, Baumol and Sidak (1994).
} 
plus any opportunity cost of providing that access. Including direct cost creates a stick, in that competitors who can supply other parts of the service at lower cost can win customers. The inclusion of opportunity cost in the optimal access price offers a carrot. When the incumbent can recover as opportunity cost the profit it will lose by granting access to another supplier, it will be willing to grant access, because it is profitable to do so. Including the ECPR's opportunity cost may not be so important in setting access prices between two networks that exchange approximately the same number of calls, because then the opportunity costs may offset each other.

Another good incentive effect of the ECPR is that it motivates efficient entry, and only efficient entry. The potential supplier who seeks access must produce at the same or lower cost in the other stages of producing the service. Such a supplier can make the final service available to consumers at the same price or a lower price, and thus may improve economic efficiency. Of course if the incumbent provider has lower costs than potential entrants, perhaps from being the first supplier and having superior technology, no other supplier will want to accept the offer of access, and the industry will remain a monopoly. Requiring access is still desirable, however, because it puts pressure on the incumbent monopoly to keep costs down and quality up; if it slips in either aspect of its service another supplier will be able to enter through the access offer.

If the ECPR is imposed on a monopoly when the final service price to consumers is at a monopoly level, that high final service price will make the opportunity cost of granting access - and thus the access price - high. On the other hand, if the final service price is at a "competitive" level, the ECPR will call for a competitive access price. In either case, the incumbent faces pressure to match entrants' costs beyond the opportunity cost in the access fee. But the efficiency of the ECPR turns on the level of the final service price. The ECPR does not deal with the final service price; it takes it as given. If competition can be so effective that it makes the final service price a competitive one, that may achieve the goal of the market efficient component pricing rule (MECPR). The MECPR has desirable properties of both carrot and stick because it rests on the price in the final service market. If the final service market is competitive, that may lower the incumbent's profit and thus the incumbent's opportunity cost of granting access. The ECPR uses the incumbent's actual cost as a reference point, thus forgoing the stick in the realm of that cost, while the MECPR imposes the stick of other firms' costs. ${ }^{26}$

If the final service market is not competitive, perhaps because it is dominated by the incumbent, then use of the incumbent's actual costs in following the ECPR takes away the stick for the incumbent, who may be motivated to overstate its direct cost of granting access to raise the price of access. And if the incumbent's opportunity cost is not covered as the ECPR requires, the incumbent loses the profit incentive to grant access and may even want to sabotage an entrant, unless of course the networks can trade connection service in kind. Both the ECPR and the MECPR presume a competitive final service market in the sense that whichever firm has a lower price can win all the business. Indeed, either the original access provider or the entrant might have lower costs and take over the entire final service market. Differentiated products or services, with less sharp and less extreme outcomes, are not envisaged. Differentiated services and final service prices can be considered in Ramsey pricing for access.

\footnotetext{
${ }^{26}$ For discussion of MECPR see Sidak and Spulber (1997).
} 


\subsubsection{Ramsey pricing for access}

Ramsey prices define an ideal, rather than a process for reaching it, but they can often be implemented by price-cap incentive arrangements. When products or services are differentiated, so demand or supply elasticities are less than infinitely elastic, access pricing can be improved by applying Ramsey pricing principles. ${ }^{27} \mathrm{~A}$ welfare maximizing problem for access can be posed and access prices can be derived to solve it. Ramsey prices will not reflect the knife-edge conditions that are implicit in use of the ECPR or MECPR, and they allow achievement of the greatest welfare even when demands are not infinitely elastic.

If there are $i=1, \ldots, n$ services to be provided that are independent of one another (all cross elasticities are zero), solving a constrained welfare problem is straightforward and yields for the $i$ th service the socially optimal Ramsey pricing rule:

$$
\left(P_{i}-C_{i}\right) / P_{i}=k / E_{i}
$$

where $k$, the Ramsey multiplier, is a constant less than 1 and $E_{i}=\left(M Q_{i} / \mathrm{M} P_{i}\right) /\left(P_{i} / Q_{i}\right)$ is the price elasticity of demand for the $i$ th service. Every ratio of price minus marginal cost over price is modified from the monopoly level by the same constant, $k$, to yield revenue merely sufficient to cover total cost. Being less than one, $k$ lowers the markups over marginal costs to a level that merely allows the firm to break even ${ }^{28}$ That pattern minimizes the loss in welfare when Ramsey prices are set above marginal costs in order to cover fixed costs and eliminate a deficit.

Suppose an incumbent monopoly provider of local service also operates long-distance Network 1, while a competitor operates Network 2 . If the competitor and the monopoly have equal cost and face identical demand elasticity, then Ramsey access prices will be the same as those defined by the ECPR. But elasticities for two services may differ, and then Ramsey prices can yield greater welfare than ECPR prices, largely because they take elasticities into account and pay attention to welfare losses. If the competitive provider of long-distance service on Network 2 faces a separate and more elastic demand than the monopoly provider on Network 1, for instance, the Ramsey price for access to the incumbent's local network will be lower than the price according to the ECPR. This follows because Network 1, with its less elastic demand, should charge a higher price to consumers, so $p_{1}>p_{2}$, and thus make a greater contribution to the fixed cost of the local network. In this way, Ramsey prices reduce the welfare loss when prices must be set high enough to cover fixed costs.

Another issue is whether Network 1 loses one customer for every unit of access granted to Network 2. If Network 2 will attract customers who would not have gone to Network 1, then Network 1 does not face a full one-to-one loss of its customers for every call delivered by Network 2 . Then the Ramsey access price can reflect just the fractional loss that Network 1 will experience for every customer won by Network 2, rather than its full profit per unit, and Network 1's incentive to offer access will still be preserved. ${ }^{29}$ This adjustment would be

\footnotetext{
${ }^{27}$ See Laffont and Tirole (1996), Armstrong, Doyle and Vickers (1996), and Armstrong and Vickers (1998) for treatments of access pricing using Ramsey principles.

${ }^{28}$ Since $k$ is less than one, and it multiplies the right-hand side of each Ramsey-price equation, it is as if a number greater than one was multiplying all of the elasticities, or $E_{i .} \mathrm{s}$, in the denominator of each right-hand side.

${ }^{29}$ For analysis of this displacement issue, and other important relations between the ECPR and Ramsey prices, see Armstrong, Doyle and Vickers (1996).
} 
needed to reflect true opportunity cost under the ECPR as well, but it can be included easily in solving for Ramsey prices when cross-elasticities are taken into account.

How can Ramsey pricing be achieved? As noted in Section 2.2 above, price-cap regulation can induce Ramsey pricing. Laffont and Tirole (1996) apply what they call a global price cap, including access as if it was one of the firm's services, and show that welfare-maximizing Ramsey prices may be induced. ${ }^{30}$ Regulation would be needed to ensure that factors like demand elasticities are correctly estimated, since distortions might otherwise be used to the incumbent monopoly's advantage. ${ }^{31}$ So incentives from price caps not only induce the stick, they also channel the carrot into welfare maximizing pricing.

\subsection{The regulation of telephone access}

Congress had been unable to agree on telecommunications legislation for decades before it passed the Telecommunications Act of 1996, which is founded on the idea that competition can function broadly in the telecommunications industry. Incumbent local exchange carriers (ILECs) are to open their networks to competitive local exchange carriers (CLECs) so the latter, by leasing facilities, may provide competing services. After some requirements are met, local exchange carriers may enter long distance markets, and of course long distance carriers may enter local markets. The Act allows telephone service providers to offer video services and cable service providers to offer telephone service. Wireless telephone service now reaches half the population. Everyone, it seems, can compete with everyone else.

Once an incumbent local exchange carrier (ILEC) complies with a 14-point checklist showing that its network is open to competition, it is allowed to send long distance calls to distant parties over its own and others' telephone networks. While the ILEC may enter the long distance market, long distance providers such as AT\&T or Sprint or a competitive local exchange carrier (CLEC) can lease facilities from an ILEC and offer local service.

Local exchange carriers (LECs) are usually subject to price-cap regulation at the state level, which elicits the carrot and the stick. Of course the carrot may bring nonoptimal pricing between interconnected networks, which price-caps will not correct when complementarities among their services are the cause. At the same time, basing prices on actual costs would forgo the stick, and thus fail to create incentives for efficiency. These realities set the stage for considering the form that access pricing has taken in practice.

There may be some advantage in having a national policy for a national network industry such as telecommunications, but it alters the simple jurisdictional boundary between state and federal regulators that existed for years. ${ }^{32}$ Historically, regulation within states was accomplished by the states, while interstate and international services were regulated by the federal government. The FCC was called upon in the Telecommunications Act to set out federal principles to guide access price setting by the states. While a case challenging the imposition of a national policy awaited resolution by the Supreme Court, some state

\footnotetext{
${ }^{30}$ Conditions are admittedly ideal in their example, because they assume future (rather than past) quantities can be used for working out the prices. See Cox and Isaac (1987) for modification of price-cap regulation, based on experimental findings, to improve its dynamic effectiveness with last-period costs as reference point.

${ }^{31}$ It is possible that relying on elasticities can yield a price below incremental cost, so it is not subsidy free and may therefore distort entry decisions. See Faulhaber (1975). Tests can be made, however, and where a Ramsey price is lower than incremental cost, the latter can be used instead as the basis for price.

${ }^{32}$ For discussion of the issues involved in this change in jurisdiction and authority, see DeBow (1998).
} 
regulators accepted the "forward looking" feature of the FCC's TELRIC rate guidelines, to which we now turn.

\subsubsection{The FCC access pricing guidelines}

The Telecommunications Act of 1996 required the Federal Communications Commission (FCC) to provide guidelines for pricing access to local telephone networks as a way to foster competition. The access prices would enable entrants into local exchange service to use the facilities of an ILEC to compete against it for local customers. The guidelines developed by the FCC introduced the stick, by encouraging competition for customers from new entrants, and they also moderated the problem of double double marginalization between networks in complementary relationships. But these attractive properties are illusory, because the FCC's standard for access pricing requires more information than the regulator can expect to have. FCC access prices are based on an idealized reference point that is very difficult to estimate. ${ }^{33}$ Application of such demanding guidelines can be expected to cause more problems as time passes and entrants come to have larger shares of LEC markets, making the guidelines more significant. By placing great responsibility on the regulator, the FCC's access pricing guidelines also fail to move the industry toward greater reliance on the competitive process, which the Telecommunications Act urged.

To set guidelines for access prices, the FCC used neither the ECPR (or MECPR), nor a system of price caps to induce Ramsey pricing, although states use price caps to regulate prices to consumers that are set by the ILECs. Access pricing under FCC guidelines was to be "forward looking", and would apply to elements of the local network. Instead of using the ILEC's actual costs for these elements, the FCC based access prices on what it called Total Element Long Run Incremental Cost (TELRIC), essentially the long run incremental cost for each service but using the best available technology, not necessarily the technology actually used by the ILEC. Notice that this avoids reference to the ILEC's own cost, and thus preserves the stick incentive, for high actual costs can lead to losses instead of high prices. ${ }^{34}$ Notice also that opportunity cost from the ECPR is not included.

Basing access prices on idealized rather than actual costs alone will tend to make them low, which has two effects. It encourages entry by CLECs and thus competition using the ILEC's facilities. But to the extent the access price is low it may discourage investment in new facilities by the CLECs. Nor will low access fees encourage investment by the ILEC, who will need to make perfect investment decisions in order for its grant of access to cover costs. Of course setting access rates rather than having them result from the carrot incentives of independent operators avoids double (or double double) marginalization.

The FCC's TELRIC guidelines have been much disputed. They were proposed for pricing unbundled network elements (UNEs), such as billing, signaling, or switching services, which meant that CLECs could pick and choose among individual provisions of already existing interconnection agreements without accepting the terms and conditions of those agreements in their entirety. The U.S. Court of Appeals for the Eighth Circuit found

\footnotetext{
${ }^{33}$ For arguments more favorable to methodologies like those in the FCC guidelines, see Falch (2002), Gasmi, Kennet, Laffont, and Sharkey (2002), and Kennet and Perez-Reyes (2002).

${ }^{34}$ Under the FCC proposal of TELRIC rates, the ILECs could not profit from the use of old and inefficient equipment, so they might be motivated to install improved resources. Of course low access prices might also discourage such investment by ILECs.
} 
the FCC rule to be unreasonable and held that the FCC had exceeded its authority. ${ }^{35}$ But the Supreme Court largely supported the FCC's authority under the 1996 Act in January 1999 and sent the case back to the appeals court on remand. ${ }^{36}$ After the appeals court decided the remanded case its decision was again appealed to the Supreme Court, which in May 2002 confirmed the FCC's authority to impose a forward looking pricing methodology (TELRIC rates) ${ }^{37}$ In addition, the Court dealt with the ILEC's offer to CLECs of unbundled network elements (UNEs), which are the signals, switches, and other elements of the local network. The Act requires that they be made available to entrants but does not say who is responsible for combining them when less than the total set of them is leased. The Court ruled that the FCC could require ILECs to combine leased UNEs for CLECs that were unable to do it themselves.

As an alternative to the ILEC's own cost, the TELRIC guideline offers a hypothetical cost, somewhat like the "replacement cost" standard that was available for rate-of-return regulation but was seldom used because it was so hard to administer. ${ }^{38}$ While TELRIC rates impose an element of the stick on ILECs, by not relying on actual costs, and they avoid double marginalization, they can interfere with decisions where the carrot is involved. For example, two interconnecting LECs will not even try to negotiate a reciprocal rate for access once the TELRIC rate, which one of the parties will prefer, is available as a default option. The TELRIC rate may bring entry by CLECs, but probably through facilities leased from the ILEC, because through its own investments a CLEC will find it hard to achieve costs that are lower than TELRIC rates. Discouraging investments by CLECs limits the possibility for innovation, which was another goal of the Act. Finally, the ILEC also may be reluctant to invest when only perfectly chosen investments will be fully compensated.

Thus, FCC guidelines for state regulation of access to telephone networks essentially set access prices. As presently constituted, the guidelines substitute for networks' decisions and thereby make regulation stronger than before, rather than weaker to invite competition as the Telecommunications Act proposes. ${ }^{39}$ A policy that attracts many entrants, so they become a significant part of the LEC market, will be hard to sustain when it encourages entrant growth without eliciting new investment. Yet it might not bring loud cries of confiscation from ILECs because they are regulated in other aspects of their business by the states, often through price-caps, and such regulation may offset short falls in access-price revenue. The TELRIC policy should not be viewed as a permanent solution, but as a temporary way to spur a form of entry to local networks that will give way in time to some later generation of access pricing rule, one that will more effectively support a competitive regime.

\subsubsection{The future of telephone networks}

Granting access to separate competing telephone networks has introduced the stick and dramatically changed the industry. Access is currently provided according to a cost reference point under much disputed federal guidelines. Mutually agreed upon access pricing

\footnotetext{
${ }^{35}$ Iowa Utilities Board, et al v. Federal Communications Commission, 120 F.3d 753 (1997).

${ }^{36}$ See AT\&T Corporation, et al.v. Iowa Utilities Board, et al., 525 U.S. 366 (1999).

${ }^{37}$ See Verizon et al. v. FCC et al., 535 U.S. 467 2002. The Review of Network Economics published a symposium on the implications of this decision in September, 2002.

${ }^{38}$ For criticism of the TELRIC guidelines and the Supreme Court's support of them see Weisman (2002).

${ }^{39}$ In February, 2003, the FCC delegated slightly more authority to the states for regulating access fees according to FCC guidelines, but made no significant change. See Stephen Labaton, "F.C.C. Leaves Most Rules on Network Leasing In Place," New York Times, February 21, 2003, p. A1.
} 
following the carrot may suffer from double double marginalization, which cannot be solved by global price caps because each network does not adjust for the complementarities involved. But rules such as the one proposed by Carter and Wright (2003) to have the larger network choose the reciprocal access price might overcome the problem. Access pricing will continue to receive attention, and innovation has quickened since restructuring began.

After the Telecommunications Act was passed, capital spending in the industry jumped from $\$ 40$ billion in 1996 to $\$ 80$ billion by 1999 , but sales did not grow with capacity, rates of return fell, and investors were unhappy. ${ }^{40}$ AT\&T reorganized into four separate companies, essentially repudiating the business plan it had pursued for the first three years after the Act was passed, and WorldCom changed its plans in a similar way. Meanwhile, prices fell for consumers which, after discovery of accounting irregularities, led to the bankruptcy of WorldCom (now MCI).

New developments continue to change the telephone industry. Wireless telephone service is booming, with many new competitors participating all around the country and more than half the population owning a wireless phone. Prices for wireless service are unregulated, and they have been falling. ${ }^{41}$ About one million wireless phones are put into service each month, some actually replacing wire-line phones. The thriving wireless alternative puts growing pressure on regulators to sort out the wire-line phone access pricing problem. Communication by e-mail and the Internet also threaten wire-line telephones. And foreign telecommunications companies can now enter domestic telecommunications markets. These forces strengthen the stick faced by wire-line networks, and they will help to motivate efficient access pricing.

\section{$4 \quad$ Restructuring electricity}

The main pricing issue in telephone networks involves access, the price charged one network to complete calls on another's network. Telephone networks do not operate separate wholesale markets for those calls, like the wholesale markets that are opened inside networks where electricity is bought and sold. Another difference is that metering devices do not allow customers to respond to price changes in electricity, except for the largest customers, and partly for this reason demand is very inelastic. Moreover, electricity cannot be stored, and when demand increases it cannot be postponed with a "busy" signal. Indeed, if demand and supply do not balance continuously the network will collapse, ${ }^{42}$ a result that can be avoided only by skillful coordination. Before restructuring, such coordination was provided by separate monopoly electric utilities in their franchised territories. Now, if electricity markets are to function successfully, new institutions must provide that coordination.

\footnotetext{
${ }^{40}$ The rush to install led to excessive network capacity. See Gretchen Morgenson, "From WorldCom, an Amazing View of a Bloated Industry," New York Times, March 16, 2003, Sec. 3, p. 1.

${ }^{41}$ The Omnibus Budget Reconciliation Act of 1993 required the FCC to auction electromagnetic spectrum for wireless communications in a way that brought at least two winners in any region and thereby served to instill competition. Prices fell from the establishment of wireless phones in the early 1990s until 1998, and since then have risen slightly, but a greater range of services was offered for the higher recent prices.

${ }^{42}$ As Weaver (forthcoming, p. 21) puts it, "It is as if, when one plane in the air develops trouble with a wing flap and starts nosediving, all other planes in the air simultaneously drop out of the sky".
} 
Access is as crucial to electricity restructuring as it was to telephones. General access to transmission grids came with the Energy Policy Act of 1992 (EPA), which built on initiatives contained in the Public Utility Regulatory Policy Act of 1978 (PURPA). PURPA and the EPA enabled independent power producers to sell power at wholesale, so a wholesale market seemed feasible. This led political leaders in high-cost states to ask whether the stick of market competition could cure inefficiencies in the industry. Electricity restructuring followed. The design of electricity markets will first be discussed in Section 4.1 , to be followed by brief treatments of major problems: market power in wholesale markets in Section 4.2, transmission problems in Section 4.3, and problems with retail competition in Section 4.4. The future of electricity market design is considered in Section 4.5 .

\subsection{Electricity market design}

A world of regulated monopoly electricity providers, who vertically integrated the functions of electricity generation, transmission, and distribution, is now giving way to a restructured world that contains markets. These restructured electricity markets have four main players: (1) companies that only generate electricity, (2) networks that transmit electricity, (3) agencies that oversee and coordinate the transmission networks, such as an Independent System Operator (ISO), an Independent Transmission Provider (ITP), or a Regional Transmission Operator (RTO), ${ }^{43}$ and (4) distribution companies, or line companies, that deliver electricity to final customers. Where there is retail competition, it involves a fifth set of players: marketing companies known as Electricity Service Providers (ESPs). They purchase power and hire a distribution or line company to deliver it to customers, whom they bill for the services.

Generating companies are open to the stick of competition. They offer wholesale electricity to the ISO at a range of quantities and prices for a given time period. Their offers of supply interact with demand in the form of quantity and price bids from line companies or ESPs. A wholesale market price for electricity results for that time period. This wholesale market is complicated. Larger generating companies possess a range of units, from base-load units that operate at low cost as long as they run all the time, to more costly peaking units that are able to run part of the time. Apart from incentives that come from controlling a range of units, generators can ordinarily profit when demand is high, and they also receive payment for being "on call" to produce if needed. While offering particular electricity services to such a market, each generator faces the costs of other generators as a stick.

Competition is sometimes also introduced at the retail level. Then merchant marketing companies, or ESPs, bid at prices and quantities to buy in the wholesale market. ${ }^{44}$ Line companies engage in bidding to get electricity for distribution to customers if there is no retail competition. ESPs are separated from generating, transmitting, or distributing facilities, but specialize in identifying consumers' needs and finding ways to serve them. They also

\footnotetext{
${ }^{43}$ There are slight differences among these organizations which we shall ignore. ITP is the ascendant appellation, but we rely on the currently common name, the ISO.

${ }^{44}$ Traditional public utilities essentially sold bundled services together, including electricity, transmission and delivery. With restructuring, electricity is produced by generating companies, sold to final users by ESPs which did not exist under monopoly organization, transmitted by transmission companies, and delivered by former distribution companies, who also step down the voltage and carry the electricity to final users.
} 
ensure that usage is recorded and bills are properly rendered and collected. A stick can be created through the competition of several ESPs, so regulation of them may be unnecessary.

The Federal Energy Regulatory Commission (FERC) regulates transmission grids, while state commissions regulate line companies. Owners of transmission grids are ordered by the FERC to offer nondiscriminatory access for all generators who want to transmit electricity. ${ }^{45}$ Access to transmission service is to be awarded on efficiency grounds, so no generator will have an advantage over others either in the convenience of its transmission service or in the rates paid for it. ${ }^{46} \mathrm{~A}$ transmission company that was part of a vertically integrated utility might maintain a generation monopoly by denying transmission access to other generators, or if it made connection for others more difficult or more costly it would certainly have an advantage in competing with them. Avoiding such outcomes is one reason some states require physical divestiture of transmission and distribution facilities from electricity generation plants as part of their restructuring plans.

Although institutions vary across states, the typical ISO operates a wholesale electricity market. It collects bids and offers for an exact time period of, say, thirty minutes, and for that time period it places offers to sell in order, from low to high prices, and it orders bids to buy from high to low prices. The ISO then finds the price at which quantities bid and quantities offered will be equal, and imposes that price on all the implied transactions. Normally all generators will receive that price, and all buyers will pay that price. Long-term contracts may exist among participants also, and a sizeable portion of electricity is usually exchanged on that basis. The ISO coordinates transmission services as well. As demands rise or fall at different points on the transmission network, congestion may develop because there are limits to the amount of electricity the wires can carry.

To maintain balance across the network, the ISO operates markets in what are called ancillary services, most importantly a market for reserve capacity to be available just in case it is needed. To facilitate the provision of such reserves, a market of the type just described is conducted on a day-ahead basis, so the ISO can see what is expected tomorrow and provide reserves to meet departures from that expected outcome when tomorrow arrives. The market for reserve generation would array offers under various readiness conditions, sometimes with fixed as well as variable payments to compensate generators for being ready to produce even if no production becomes necessary. These reserves are also used for congestion management across the transmission system by providing power where it is needed but where transmission congestion prevents it from being transmitted. In some parts of the

\footnotetext{
${ }^{45}$ In 1996, the FERC issued two orders for transmission systems that provide a framework to support the functioning of competition in a market for electricity. First, in its Order 888, FERC required the owner of a transmission line to offer nondiscriminatory access to any company wishing to send electricity to any wholesale buyer, such as a local distribution system or a power marketer. See Order 888, "Promoting Wholesale Competition through Open Access Non-Discriminatory Transmission Services by Public Utilities; Recovery of Stranded Costs by Public Utilities and Transmitting Utilities," issued April 24, 1996, 75 FERC ' 61,080 . Second, Order 889 required any party that operated transmission facilities in interstate commerce to participate in an Aopen-access, same-time information system, @ to provide information electronically about available capacity, prices, and other necessary information for a market in power to operate. See Order 889, "Open Access Same-Time Information Systems," issued April 24, 1996, 75 FERC '61,078.

${ }^{46}$ FERC's Order 2000 focuses on impediments to competition in transmission systems, largely because they were built by private utilities who could discriminate in favor of their own, or their affiliate's, marketing activities. This order is available at http://www.ferc.gov.
} 
United States this coordinating function is provided by RTOs, one of which oversees power supplies in each of the ten regional reliability councils in the North American Electricity Reliability Council (NERC). ${ }^{47}$

In order to avoid conflicts of interest, the ISO normally is not allowed to own generation capacity, although it might own and operate a transmission grid connecting generating companies with distribution companies. ${ }^{48}$ Questions about incentives in ISOs remain to be answered, because it is not clear that totally efficient, unbiased, and ownerless oversight is possible.

This brief sketch cannot capture the complexity of electricity markets, but it conveys main ideas and may hint at many of the problems that can develop. Market power can arise in generation and transmission operations, for example. Introducing retail competition has been difficult also in part because of difficulties in the transition to markets. To overcome some of these problems, the FERC proposed a Standard Market Design (SMD), ${ }^{49}$ a set of policies and procedures intended to induce efficiency incentives by using the best rules yet discovered. Major problems with electricity restructuring can briefly be described.

\subsection{Market power in the wholesale market}

If the stick of competition is weak, the carrot may bring inefficiencies due to market power. To avoid such inefficiency, generating companies are evaluated by the FERC to determine whether they have market power, and if they do their prices must be approved by FERC. ${ }^{50}$ Only if a generating company has no market power is it allowed to choose its own offer prices for the wholesale market and operate under the carrot of profit. Initially, concentration measures were used by the FERC to judge market power, and under this standard generating companies were seldom found to have market power. But concentration measures are inappropriate to judge market power when separate units of capacity are controlled by suppliers.

Holt, Langan and Villamil (1986) showed in experimental markets how control over marginal units of capacity can give market power to a firm that does not have a large market share. What is important is whether one firm controls capacity in the range between total capacity in the market and total demand. In that position, one party can influence market price by withholding capacity, so there can be market power and incentive to use it. Rassenti, Smith, and Wilson (2000) found support for this view of market power in experimental

\footnotetext{
${ }^{47}$ Thirty million people went without power in the Northeastern United States during a shocking "blackout" on November 19, 1965, which led to formation of a voluntary industry organization called the North American Electric Reliability Council (NERC). Its ten regional councils have authority to intervene and coordinate the generation and transmission of power by member utilities. The regional councils are charged with keeping electricity reliable in three synchronized electricity grids that cover Canada, the United States and parts of Mexico. They were eminently successful in this task until August 14, 2003, when the Northeastern United States suffered an even more devastating blackout that was probably due in part to the increased burdens that restructuring has brought to transmission facilities.

${ }^{48}$ It might be possible to have ISO's as large as the three synchronized electricity grids in North America. Alternatively, ISO's might be created in each state in the U.S., especially if this form of competition develops separately in each state. As noted, an RTO operates in each of the ten regional councils in the NERC. One regional council lies within the borders of Texas, and its RTO serves as ISO for the Texas electricity market.

${ }^{49}$ The Standard Market Design is a 640 page document, available at http://www.ferc.gov.

${ }^{50}$ See Wolak (forthcoming).
} 
electricity markets. In late 2001, the FERC moved toward a new Supply Margin Assessment (SMA) test to evaluate market power that compares a firm's capacity with the difference between total capacity and peak demand, as this experimental work suggests.

Withholding capacity from the market (called physical withholding), or bidding some units at high prices (called economic withholding), can be profitable when capacity is scarce. Generating companies feel the carrot, and the stick is weak when capacity is scarce. Withholding can raise the market price, which will benefit other units that the large generating company still has in the market. This means the incentive for withholding is independent of others (generators need not collude), which makes it a general problem in wholesale electricity markets. Withholding grows less serious as more power is committed under bilateral long term contracts, since parties to such contracts cannot profit from a high spot price. $^{51}$ For California, where for some time bilateral contracts were not much used because they were not enforced, Borenstein, Bushnell and Wolak (2002) found that market power could be blamed for 59 percent of the increase in wholesale electricity prices from summer 1999 to the crisis in summer 2000. They estimated competitive prices, based on costs that included influences like increased natural gas prices and the more costly generating units that are pressed into service when demand was high. Against such a benchmark they found market prices substantially higher. ${ }^{52}$

England and Wales have operated a competitive wholesale electricity market since 1990 that has shown signs of market power. ${ }^{53}$ In 2001 , the basis for setting price in their wholesale market was changed by the adoption of a New Electricity Trading Arrangement (NETA). Until NETA, participation in the wholesale Pool was compulsory and bilateral contracts took the form of "contracts for differences" around the Pool price. Under NETA, bilateral contracting soon became the basis for the vast majority of transactions. Balancing transactions to coordinate the system are no longer settled at a uniform price, but instead follow a pay-as-bid system in which offers that are accepted receive whatever they offered instead of a uniform price. ${ }^{54}$ Only a small fraction of transactions take this pay-as-bid form. Electricity price has declined since NETA, perhaps because the generating sector is increasingly competitive, and bilateral contracts reduce opportunities for profitable withholding.

The FERC Standard Market Design (SMD) includes many elements aimed at mitigating market power. The main weapon proposed for limiting market power in wholesale markets is to put a cap, or upper limit, on offers. When generating capacity is scarce (defined relative to

\footnotetext{
${ }^{51}$ Long-term contracts can reduce the incentive to withhold, because with more units already committed on a long-term basis there is less to be gained from a short-run price increase. For analysis of this contracting effect see Green (1999).

${ }^{52}$ For analysis of the role of energy trading in the California crisis, plus a wealth of other information, see Weaver (forthcoming).

${ }^{53}$ For evidence of market power in England and Wales see Wolak and Patrick (1997) and Wolfram (1999).

${ }^{54}$ For description of the England and Wales procedures, see Green (forthcoming). For criticism of pay-asbid procedures in wholesale electricity markets, see Kahn, Cramton, Porter, and Tabors (2001). If competition is strong enough, incentives in the uniform-price market are like those in a second price auction: bids and offers can be entered at valuations or costs in a nonstrategic way because the individual bid or offer is not expected to determine price. The classic analysis of these auction procedures is by Vickrey (1961). A pay-as-bid market is like a first-price auction in which participants must guess the bids and offers of others and try to beat them, so they behave strategically, and may set lower prices to win contracts.
} 
peak demand), price caps automatically become effective to limit the advantage that scarcity might otherwise give to generators. Another, higher, cap moderates the problem of inelastic demand, which is exacerbated by metering costs that keep consumers from facing higher prices when electricity is scarce. The SMD also provides for planning, to ensure adequacy of generation and transmission resources and thus to limit scarcity.

\subsection{Transmission problems}

The transmission networks were built by monopoly electric utilities, and were designed to control the transmission of electricity in the areas those utilities served. Connections between such networks were mainly to exchange power for emergencies, not to create an integrated network. Moreover, a generation company in such a local network may not want the network expanded if that will bring competing electricity from other areas (always resist the stick). The FERC's SMD offers a host of policies to contain such motivation, including more enforcement of open access requirements. ${ }^{55}$

Transmission lines can only carry so much electricity, or they will melt from excessive heat. So transmission is limited to rated capacity levels. Congestion on the wires can then prevent transmission into areas of high demand, called "load pockets", and the resulting scarcity can create local market power. Even without market power, when electricity cannot be delivered into an area because of congestion the price on the importing side of the congestion can be high. The cost of electricity is higher on the importing side because older and less efficient facilities must be used there to meet demand when electricity from other locations cannot get past congested lines.

To help deal with load pockets, a separate local price is set for areas that cannot receive as much power as desired because of line congestion. These local prices are called locational marginal prices (LMPs), and they determine fees for using the congested lines. The difference in prices at two ends of a congested line provides an ideal congestion charge for use of that congested line, as it puts the cost of congestion on those who cause it. The FERC's SMD recommends such pricing. A variety of transmission rights instruments help those transmitting electricity to hedge against the uncertainties of fluctuating congestion fees.

Investment signals from congestion charges constitute a "lumpy" carrot that complicates private enterprise investment decisions in transmission facilities. Congestion may produce a large congestion charge on a line, for instance, but expanding the line eliminates the congestion and with it the financial benefit of building the line. This problem of on-again, off-again investment signals might suggest public ownership as a possible arrangement for financing and controlling transmission investment. ${ }^{56}$ But some degree of private ownership may be workable with clever arrangements that preserve efficiency incentives. ${ }^{57}$

\footnotetext{
${ }^{55}$ For description of restructured transmission operations see Cameron and Cramton (1999).

${ }^{56}$ Central control may not solve all problems. England adopted a regulated national grid company (National Grid Transco), but still had a blackout over 40 percent of London on August 28, 2003. See Heather Timmons, "Blackout in Britain Raises Questions About Following Its Example," New York Times, September 2, 2003, p. C4.

${ }^{57}$ For devices to facilitate sound private investment incentives see Hogan (forthcoming) and Joskow and Tirole (2000).
} 


\subsection{Retail competition}

Retail competition in electricity has not been a great success in the United States. Large numbers of residential consumers have not switched to new electricity service providers, mainly because two transition problems have blocked the carrot and limited the scope for competitors' price reductions. First, residential consumers were favored by low regulated rates, and lowering prices to win political support for restructuring is more difficult from an already low starting point. Indeed, without new cost reductions, prices for residential consumers might rise with restructuring because costs should have a clearer influence on prices, and costs for residences are higher than old regulated prices would indicate. ${ }^{58}$

Second, there is the problem of "stranded costs", the reduction (usually) in asset values that follows from the introduction of competition. ${ }^{59}$ Since many regulated electric utilities made investments that at the time were deemed prudent, under a traditional "regulatory compact" the values of those investments merited protection. But when a charge must be included to compensate investors for such stranded costs it is still harder for competitors to offer consumers lower prices. Raising extra money for stranded costs, while also lowering prices from what was a favored reference point, presents a double barreled challenge for retail competition.

Almost all state restructuring plans have lowered prices to residential consumers and provided payment for stranded costs. As a consequence, prices were so low that there was not much room for competing electricity service providers to enter the market. As incentive to switch to a new ESP, consumers seem to require at least a five percent reduction in their rate, and the transition situation for electricity restructuring seldom allows that. The stranded cost problem grows smaller with the passage of time, and time also makes old regulated rates a more distant reference point. So the passage of time may improve the opportunity for retail competition.

\subsection{The future of electricity markets}

Electricity restructuring faces a host of carrot and stick incentive problems. Among the most important are transmission system operation, where a mixture of integrated utilities and ISOs operate with different rates, terms, and conditions. As a result, independent generators do not always have reliable access on equal terms as affiliates of integrated utilities. Transmission system investment decisions also need collective planning and coordination. A major focus of the FERC's Standard Market Design is transmission management, with procedures and institutions to overcome barriers that presently handicap some generators and prevent markets from functioning efficiently. ${ }^{60}$

Market power is a serious problem of too much carrot and not enough stick, and it arises especially in wholesale electricity markets. New conceptions of market power are relevant and new devices are needed to deal with it. But many devices are being considered. England

\footnotetext{
${ }^{58}$ Residential demand fluctuates more than commercial and industrial demands, and for that as well as other reasons residences tend to be more costly to serve.

${ }^{59}$ Also, in efforts going back to 1978 to stimulate a wholesale market the federal government created a class of independent generators and required electric utilities to buy their power, sometimes at high rates. The effects of these uneconomical contracts are harmful under competition, and they add to stranded costs.

${ }^{60}$ Regulatory lessons from the California experience are valuable and are described by Joskow (2001) and Wolak (forthcoming).
} 
and Wales shifted to bilateral contracts and adopted pay-as-bid pricing for balancing transactions, for example, and a variety of means to mitigate market power has been applied in existing markets. Broadening transmission networks will also help. The FERC's SMD includes many methods for mitigating market power. Forcing generation companies to become smaller through divestiture is still a possibility.

Most consumers have no way to respond to real-time electricity prices. Even crude timeof-use pricing will be valuable, because responses to prices can enhance efficiency. The prices in our homes do not respond to short-run supply conditions because metering electricity by time of use is costly and few arrangements have been made to communicate price information on a continuous basis. When the price of electricity in residences does not change between peak and off peak demand conditions, despite its scarcity at peak times, consumers can show no elasticity in their demands. ${ }^{61}$ No price signal tells us to curb our consumption, even though peak electricity might be extremely costly, so a carrot is blocked from reaching us. An opportunity to respond to price signals currently exists only for larger commercial and industrial customers. ${ }^{62}$

Three main ways of eliciting consumer response can be noted. First is time-of-use pricing, which takes advantage of general patterns of demand that occur by time of day and season of year and sets price accordingly. The advantage of such pricing is that consumers can be informed ahead of time of the price they can expect to pay by time of day, so they can arrange their activities to use electricity when it is less costly (do the laundry at night). Second is real-time pricing, which is more ambitious. ${ }^{63}$ Real-time prices adjust to actual conditions of electricity costs. Of course real-time prices must be communicated to users so they can react, which requires more expensive meters. But in a large commercial building simply raising temperatures a couple of degrees in summer to reduce air conditioning when the electricity price is high (a move that can be programmed automatically) can yield significant savings. ${ }^{64} \mathrm{~A}$ third means of motivating reactions is the interruptible service contract, mainly for commercial and industrial users. Here the user agrees in advance to curtail electricity use when it is scarce. The user agrees to a fixed fee to protect a chosen level of usage against interruption, giving the user a trade-off between protection and cost.

Ideally, consumer responses can influence wholesale markets. That is, wholesale buyers may make better estimates of needs, knowing that consumers will respond to increases in prices, so wholesale demand will become more elastic. This insinuation of market forces reveals a main benefit of introducing markets into electricity networks. Not only can the stick of competition force efficiency, but - if soundly constrained - the carrot opens opportunity for those who ultimately are served to respond to the true costs of the services they receive.

\footnotetext{
${ }^{61}$ In northern European countries, where time-of-use pricing is common, homes use heat-storage devices at night when rates are low so heat can be released during the day in order to avoid paying higher daytime rates.

${ }^{62}$ See Edwin McDowell, "Cooling the Empire State Building on the Cheap," New York Times, April 16, 2003, p. C 7. Managers of the Empire State Building say they saved \$48,000 last summer (and would have saved $\$ 200,000$ if they had been able to start before August) by switching between cooling methods depending on current prices. Under deregulated pricing they are planning to make ice at night when electricity is cheap and use it in their cooling system during the day when rates are high.

${ }^{63}$ A suggestive proposal for real-time Internet pricing is provided by Mackie-Mason and Varian (1994).

${ }^{64}$ See Borenstein (forthcoming).
} 


\section{Conclusion}

Restructuring former monopoly network industries to introduce competition brings a rich combination of market problems and possibilities. The problems of introducing markets inside networks are serious, and careful design is needed to have the stick of competition discipline the carrot of profit, because effective markets will not evolve on their own. Pricing motives do not always serve efficiency in telephone networks, and creating markets in electricity networks is even more ambitious. Yet despite problems the opportunities in both cases are considerable. The pace of innovation in the telephone industry is remarkable today, and would probably not have been matched by the old regulated-monopoly regime. Electricity markets require new thinking about market power, plus a wide variety of new arrangements to provide efficiency incentives, not the least of which would allow consumers to respond to the changing price of electricity. In both industries, ultimate benefits in production and allocative efficiency appear to be worth the costs of change.

\section{$6 \quad$ References}

Ai, Chunrong and David E. M. Sappington (2002) "The Impact of State Incentive Regulation on the U.S. Telecommunications Industry," Journal of Regulatory Economics, 22: 107-32.

Andreoni, James, William Harbaugh, and Lise Vesterlund (2003) "The Carrot or the Stick: Rewards, Punishments, and Cooperation," American Economic Review, 93: 892-902.

Armstrong, Mark, Chris Doyle and John Vickers (1996) "The Access Pricing Problem: A Synthesis," Journal of Industrial Economics, 44: 131-50.

Armstrong, Mark and John Vickers (1998) "Access Pricing with Deregulation: A Note," Journal of Industrial Economics, 46: 115-21.

Averch, Harvey and Leland L. Johnson (1962) "Behavior of the Firm under Regulatory Constraint," American Economic Review, 52: 1053-69.

Baumol, William J. (1968) "Reasonable Rules for Rate Regulation: Plausible Policies for an Imperfect World," in A. Phillips and O. E. Williamson, eds., Prices: Issues in Theory, Practice, and Public Policy. Philadelphia, Pa.: University of Pennsylvania Press.

Baumol, William J. and Gregory J. Sidak (1994) "The Pricing of Inputs Sold to Competitors," Yale Journal on Regulation, 14: 145-63.

Borenstein, Severin "Time-Varying Retail Electricity Prices: Theory and Practice," in Electricity Deregulation: Where To From Here? eds. J.M. Griffin and S. Puller. University of Chicago Press, forthcoming.

Borenstein, Severin James B. Bushnell and Frank A. Wolak (2002) "Measuring Market Inefficiency in California's Wholesale Electricity Market," American Economic Review, 92: 1376-1405. 
Cameron, Lisa and Peter Cramton (1999) "The Role of the ISO in U.S. Electricity Markets: A Review of Restructuring in California and PJM," Electricity Journal, 12: 71-81.

Carter, Michael and Julian Wright (2003) “Asymmetric Network Interconnection,” Review of Industrial Organization, 22: 27-46.

Chadwick, Sir Edwin (1859) "Results of Different Principles of Legislation and Administration in Europe: of Competition for the Field, as Compared with the Competition within the Field of Service," Journal of the Royal Statistical Society, 22: 381-420.

Cox, James C., and R. Mark Isaac (1987) "Mechanisms for Incentive Regulation: Theory and Experiment," RAND Journal of Economics, 18: 348-59.

DeBow, Michael E. (1998) “Congress, Federal Courts, and Administrative Agencies: How Much Authority Did Congress Give the Federal Communications Commission to Hasten Telecommunications Deregulation?" PREVIEW of United States Supreme Court Cases, American Bar Association, 49-54.

DeGraba, Patrick (2001) "Efficient Interconnection for Competing Networks When Customers Share the Value of a Call," October, Charles River Associates Working Paper.

Demsetz, Harold (1968) "Why Regulate Utilities," Journal of Law and Economics, 11: 5565 .

Dharan, Bala, and Nancy Rapoport, eds., Enron: Corporate Fiascos and Legal Implications, Cincinnati, $\mathrm{OH}$ : Anderson, forthcoming

Eckel, C.C. (1987) “Customer Class Price Discrimination by Electric Utilities," Journal of Economics and Business, 39: 19-33.

Falch, Morten (2002) "TELRIC - The Way Towards Competition? A European Point of View," Review of Network Economics, 1: 147-53.

Faulhaber, Gerald R. (1975) “Cross Subsidization: Pricing in Public Enterprises," American Economic Review, 65: 966-77.

Gasmi, Farid, D. MarKennet, Jean-Jacques Laffont, and William Sharkey (2002) Cost Proxy Models and Telecommunications Policy, Cambridge, MA: MIT Press.

Green, Richard (1999) “The Electricity Contract Market in England and Wales," Journal of Industrial Economics, 47: 107-24.

Green, Richard "Restructuring the Electricity Industry in England and Wales," in Electricity Deregulation: Where To From Here? eds. J.M. Griffin and S. Puller. University of Chicago Press, forthcoming.

Griffin, James M. and Steven Puller Electricity Deregulation: Where To From Here? University of Chicago Press, forthcoming. 
Hogan, William W. "Transmission Market Design," in Electricity Deregulation: Where To From Here? eds. J.M. Griffin and S. Puller. University of Chicago Press, forthcoming.

Holt, Charles, A., L. Langan and A. Villamil (1986) "Market Power in Double Oral Auctions," Economic Inquiry, 24: 107-23.

Jones, Fred (1983) Input Biases under Rate-of-Return Regulation, New York: Garland Press.

Joskow, Paul L. (2001) “California’s Energy Crisis," Oxford Review of Economic Policy, Autumn, 17: 365-88.

Joskow, Paul L. "The Difficult Transition to Competitive Electricity Markets in the U.S.," in Electricity Deregulation: Where To From Here? eds. J.M. Griffin and S. Puller. University of Chicago Press, forthcoming.

Joskow, Paul L. and Jean Tirole (2000) "Transmission Rights and Market Power on Electric Power Networks," RAND Journal of Economics, 31: 450-87.

Kahn, Alfred E. (2003) "Regulatory Politics as Usual,” AEI-Brookings Joint Center, Policy Matters Paper 03-3, March.

Kahn, Alfred E., Peter C. Cramton, Robert H. Porter and Richard D. Tabors (2001) "Uniform Pricing or Pay-as-Bid Pricing: A Dilemma for California and Beyond," Electricity Journal, 14: 70-79.

Kearney, Joseph D., and Thomas W. Merrill (1998) “The Great Transformation of Regulated Industries Law," Columbia Law Review, 98: 1323-1409.

Kennet, D. Mark, and Raul Perez-Reyes (2002) "Beyond the Rhetoric: An Introduction to Implementing TELRIC," Review of Network Economics, 1: 155-67.

Laffont, Jean-Jacques, and Jean Tirole (1987) “Auctioning Incentive Contracts," Journal of Political Economy, 95: 921-37.

Laffont, Jean-Jacques and Jean Tirole (1996) "Creating Competition through Interconnection: Theory and Practice," Journal of Regulatory Economics, 10: 227-256.

Laffont, Jean-Jacques and Jean Tirole (1998a) "Network Competition: I. Overview and Nondiscriminatory Pricing," RAND Journal of Economics, 29: 1-37.

Laffont, Jean-Jacques and Jean Tirole (1998b) "Network Competition: II. Price Discrimination," RAND Journal of Economics, 29: 38-56.

Lipsky, Jr., Abbott B., and J. Gregory Sidak (1999) "Essential Facilities," Stanford Law Review, 51: 1187-1248.

Loeb, Martin, and Wesley Magat (1979) “A Decentralized Method for Utility Regulation,” Journal of Law and Economics, 22: 399-404. 
McAfee, R. Preston and John McMillan (1987) "Competition for Agency Contracts," RAND Journal of Economics, 18: 296-307.

Michaels, Robert J. (1993) “The New Age of Natural Gas,” Regulation, 17: 68-79.

Montgomery, Robert (1931) “Judicial Fair Return and the Price Level," Southwestern Social Science Quarterly, 12: 221-53.

Ramsey, Frank (1927) “A Contribution to the Theory of Taxation,” Economic Journal, 37: 47-61.

Rassenti, Stephen J., Vernon L. Smith, and Bart Wilson (2000) "Market Power in Electricity Networks," Working Paper, George Mason University.

Sappington, David E.M. (1980) "Strategic Firm Behavior under a Dynamic Regulatory Adjustment Process," Bell Journal of Economics, 11: 360-72.

Sappington, David E.M., and Dennis L. Weisman (1996) Designing Incentive Regulation for the Telecommunications Industry. Cambridge, MA: MIT Press.

Sherman, Roger (1976) "An Antimonopoly Policy Proposal for Newspaper Markets," Industrial Organization Review, 2: 17-28.

Sherman, Roger (1989a) The Regulation of Monopoly. Cambridge: Cambridge University Press.

Sherman, Roger (1989b) "Pricing Periods under Rate-of-Return Regulation," Journal of Regulatory Economics, 1: 163-73.

Sherman, Roger (2001a) “The Future of Market Regulation," Southern Economic Journal, 67: 782-800.

Sherman, Roger (2001b) "Optimal Worksharing Discounts," Journal of Regulatory Economics, 19: 81-92.

Sherman, Roger, and Michael Visscher (1982) "Rate-of-Return Regulation and Two-Part Tariffs," Quarterly Journal of Economics, 97: 27-42.

Shleifer, A. (1985) “A Theory of Yardstick Competition," RAND Journal of Economics, 16: 319-27.

Temin, Peter (1987) The Fall of the Bell System. New York: Cambridge University Press.

Vickrey, William S. (1961) “Counterspeculation, Auctions, and Sealed Tenders," Journal of Finance, 16: 8-37.

Vogelsang, Ingo and Jorg Finsinger (1979) "A Regulatory Adjustment Process for Optimal Pricing by Multiproduct Monopoly Firms,” Bell Journal of Economics, 10: 157-71. 
Weaver, Jaqueline L. "Can Energy Markets Be Trusted?: The Effect of the Rise and Fall of Enron on Energy Markets," in Enron: Corporate Fiascos and Legal Implications, eds. B. Dharan and N. Rappoport. Cincinnati, OH: Anderson, forthcoming

Weisman, Dennis L. (1993) “Superior Regulatory Regimes in Theory and Practice," Journal of Regulatory Economics, 5:355-66.

Weisman, Dennis L. (1994) “Why Less May Be More Under Price-Cap Regulation,” Journal of Regulatory Economics, 6: 337-61.

Weisman, Dennis L. (2002) "Did the High Court Reach a New Low in Verizon v. FCC?" Review of Network Economics, 1: 90-105.

Wellisz, S.H. (1963) "Regulation of Natural Gas Pipeline Companies: An Economic Analysis," Journal of Political Economy, 55: 30-43.

Williamson, Oliver E. (1976) "Franchise Bidding for Natural Monopolies In General and with Respect to CATV," Bell Journal of Economics, 7: 73-104.

Willig, Robert D. (1979) "Customer Equity and Local Measured Service," in Joseph A. Baude, et al., eds., Perspectives in Local Measured Service. Kansas City: Rocky Mountain Telephone Company.

Wolfram, Catherine D. (1999) "Measuring Duopoly Power in the British Electricity Spot Market," American Economic Review, 89: 805-26.

Wolak, Frank A., and Robert H. Patrick (1997) "The Impact of Market Rules and Market Structure on the Price Determination Process in the England and Wales Electricity Market," POWER Working Paper PWP-047, University of California Energy Institute, April.

Wolak, Frank A. (1998) "Price-Cap Regulation in Newly Privatized Industries," Oxford Energy Forum, 12-14, available at http://www.stanford.edu/ wolak/.

Wolak, Frank A. "Lessons from the California Electricity Crisis," in Electricity Deregulation: Where To From Here? eds. J.M. Griffin and S. Puller. University of Chicago Press, forthcoming.

Wright, Julian (1999) "International Telecommunications, Settlement Rates, and the FCC," Journal of Regulatory Economics, 15: 267-91. 